\title{
Fluidized bed drying of petals of Echium amoenum Fisch. and C.A. Mey: energy analysis and carbon footprint
}

Nadi, F. ${ }^{a^{*}}$; Atuonwu, J.C. ${ }^{\text {b }}$

a Department of Agricultural Machinery Mechanics, Azadshahr Branch, Islamic Azad University, Azadshahr, Iran

${ }^{\mathrm{b}}$ Centre for Sustainable Energy use in Food Chains, Brunel University London, Uxbridge, Middlesex, UB8 3PH, the United Kingdom.

*E-mail of the corresponding author: f.nadi@iauaz.ac.ir

\begin{abstract}
The energy performance and carbon footprint associated with the fluidized bed drying of petals of Echium amoenum Fisch. and C.A. Mey are experimentally evaluated at three temperatures $\left(40,50,60^{\circ} \mathrm{C}\right)$ and air velocities $(0.50,0.75,1.00 \mathrm{~m} / \mathrm{s})$. The maximum and minimum specific energy consumption are observed to occur at $40^{\circ} \mathrm{C}$ and $1 \mathrm{~ms}^{-1}(79.18 \mathrm{MJ} / \mathrm{kg})$ and $60^{\circ} \mathrm{C}$ and $0.5 \mathrm{~m} / \mathrm{s}$ $(22.60 \mathrm{MJ} / \mathrm{kg})$, respectively. The greenhouse gas emission is in the range, 0.10 $8.40 \mathrm{kgCO} \mathrm{O}_{2} \mathrm{eq}$, varying with drying conditions in the same manner as energy consumption, with natural gas-fired systems performing better than oil-fired systems. High-temperature, low-air velocity drying is thus, favourable for energy-efficient and sustainable fluidized bed drying of the petals.
\end{abstract}

Keywords: fluidized bed dryer; greenhouse gas; specific energy consumption; Iran. 


\section{Introduction}

Echium amoenum Fisch. and C.A. Mey grows in a narrow region of northern Iran and the Caucasus [1]. Its dried violet-blue petals have medicinal (demulcent, anti-inflammatory, analgesic, sedative tonic, tranquillizing and diaphoretic) properties, and are useful as remedies for cough, sore throat and pneumonia [2, 3]. Hence, it is important for the drying of these petals to be energy-efficient and sustainable, while yielding high-quality products.

From ancient times, solar energy has been used to dry agricultural products. However, sun drying has several disadvantages such as poor food quality, insufficient control over the drying process, long drying times and contamination, all of which, could be avoided using industrial dryers [4]. The control of thermal treatment conditions is important during industrial drying of medicinal plants as the final product quality largely depends on the treatment conditions. In general, the drying temperature of medicinal plants should not exceed a certain level, to retain active compounds [5]. In this regard, drying in the fluid bed is attractive due to the homogeneous heat treatment of products, which allows better control of the conditions even at temperatures higher than those that cause thermal degradation of the product $[6,7]$.

Fluidization also has several other benefits such as increasing moisture uniformity, facilitating the use of higher drying temperatures and hence, increasing drying capacity, allowing for better mass and heat transfer, smaller-size dryer chambers, lower costs and higher-quality products [8].

As drying is an energy-intensive process, accounting for about $10-25 \%$ of the national industrial energy of the developed world $[9,10]$, it is very important that drying processes are energy-efficient. It is therefore not surprising that energy efficiency has over the years been a key driver of research and development in drying technology [10]. Preserving limited fossil fuels, reducing carbon footprint to combat climate change and improving the economics of drying-related processes are clear motivations for reducing energy consumption in drying [11]. The first step in identifying opportunities to save energy in drying processes, is an in-depth analysis of energy use. The evaporation load to remove water from the product under different drying conditions indicates energy consumption [11].

Energy consumption affects global warming, which in turn, affects humans and ecosystems in different ways: rising temperatures, changes in rainfall and rainfall rates, changes in the rate of melting of snow and ice, rising sea levels, changes in the geographical population distribution and even the extinction of some animals and plants [12].

Actions aimed at reducing energy usage must therefore be taken urgently in all processing activities. For drying in particular, using renewable energy sources, optimizing every part of 
the process and using control devices to detect and minimize GHG injection into the atmosphere are some of the possible actions.

Singh et al. [13] studied $\mathrm{CO}_{2}$ production during potato slice drying. They compared the $\mathrm{CO}_{2}$ emissions of the sun, fossil fuels (coal, diesel fuel, natural gas) and electricity. Results showed that replacing coal with solar energy significantly reduced carbon emissions.

Kumar and Kandpal [14] analyzed the carbon emission potentials of drying various products using solar energy and other fuels in India. It was reported that increasing the proportion of solar energy, relative to the other fuels (coal, natural gas, wood) during agricultural product drying could lead to significant reductions in carbon emissions.

Piacentini and Mujumdar [12] studied climate change due to the drying of agricultural products. Given the high energy-demand of the drying operation, the authors proposed the use of renewable sources, optimizing the drying process and adopting energy efficient practices to reduce GHG emissions.

Motevali and Tabatabaei [15] studied $\mathrm{SO}_{2}, \mathrm{CO}_{2}$ and $\mathrm{NO}_{\mathrm{X}}$ emissions during the drying of dogrose using hot-air, infrared, hybrid hot air-infrared, microwave, hot air-microwave, vacuum, and hybrid photovoltaic-thermal solar dryers. The results showed that GHG emissions increased with temperature and air velocity in the hot air dryer, and reduced when infrared and hybrid hot air-infrared energy are used instead of hot air. The GHG emissions of hybrid photovoltaic-thermal solar dryers were less than the emissions of the hot air dryer.

The literature review shows little research on the GHG emissions of dryers. The aim of this research is to explore the energy consumption and effects of different drying conditions on greenhouse gas emissions for petals of Echium amoenum Fisch. and C.A. Mey.

\section{Materials and Methods}

\subsection{Experimental procedure and energy analysis}

A laboratory-scale fluidized bed dryer (details can be found in [16]) constructed at the Department of Agricultural Machinery Engineering of Azadshahr University, Iran, was used to conduct the drying experiments. It consisted of an air-heating device, chamber, and control systems for air and temperature. The fluidized bed chamber, made of stainless steel with inside dimensions of $250 \mathrm{~mm} \times 250 \mathrm{~mm} \times 300 \mathrm{~mm}$, is connected with a fan, a duct made of stainless steel to supply air, while the distributor plate, with thickness of $1 \mathrm{~mm}$ and holes of $3 \mathrm{~mm}$ in diameter, was tightly fixed to the bottom of the chamber. The fluidizing air is supplied by a $1.5-\mathrm{kW}$ blower, while an anemometer is used to regulate the air velocity manually. The heating unit consists of three fin heaters each of $800 \mathrm{~W}$ power, using thermostat-type temperature controls in order to adjust the desired drying temperature. 


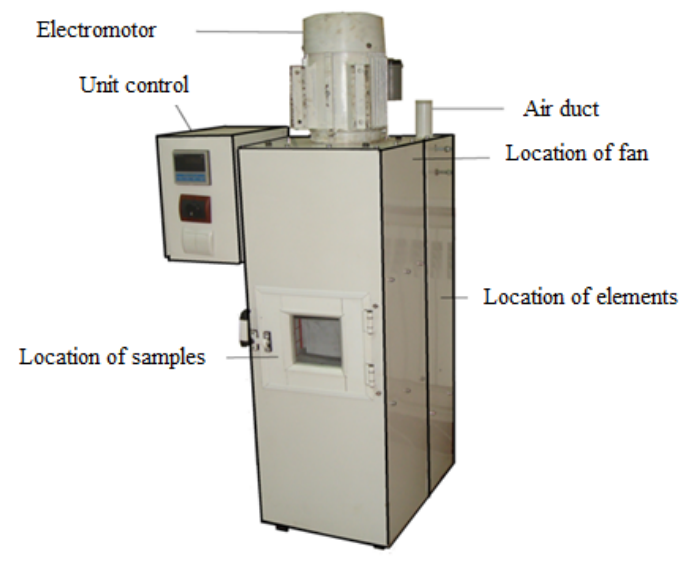

Fig. 1 Fluidized bed dryer

The total energy consumed during the experimental drying operation was estimated from the sum of the thermal and mechanical energies. Equation (1) was used to calculate the thermal energy for different temperatures.

$$
E_{t h}=\left(A \cdot v \cdot \rho_{a} \cdot C_{a} \cdot \Delta T\right) \cdot t
$$

where, $A, v, \Delta T, t, \rho_{a}$ and $C_{a}$ are the cross-sectional area of the distributor plate, the air flow rate, temperature difference between the dryer inlet and ambient air, drying time, density and specific heat capacity of the inlet air, respectively. The density and specific heat capacity of the air were respectively calculated [17] as:

$$
\begin{aligned}
& \rho_{a}=\frac{353.049}{T_{a}} \\
& C_{a}=1.04841-\frac{3.83719 T}{10^{4}}+\frac{9.45378 T^{2}}{10^{7}}-\frac{5.49031 T^{3}}{10^{10}}+\frac{7.92981 T^{4}}{10^{14}}
\end{aligned}
$$

The mechanical energy used to move the air by the blower was determined by [18]:

$$
E_{m e c}=\Delta P v A t
$$

where $\Delta P=0.5 f \mathrm{~h} v^{2} \rho$, with $\Delta P$ as the pressure drop, $h$, product thickness, and $f$, the resistance to airflow.

Specific energy consumption SEC $(\mathrm{kJ} / \mathrm{kg})$ is the total energy required to remove $1 \mathrm{~kg}$ of water from the product during the drying process and is expressed by the following equation. 


$$
S E C=\frac{E_{t h}+E_{m e c}}{m_{w}}
$$

where, $m_{w}$ is the mass of removed water from the product during the drying operation. It is obtained from equation (6).

$$
m_{w}=\frac{W_{0}\left(M_{0}-M_{f}\right)}{100-M_{f}}
$$

where $W_{0}$ is initial weight,,$M_{0}$ is initial moisture content and $M_{f}$ is final moisture content.

\subsection{GHG emissions}

The main source of power in many dryers is electricity [15]. Hence, the GHG emissions from the driving power plant indicates the amount of energy consumed during the drying process. The conventional power generation system in Azadshahr city, courtesy of Neka Power Plant, is a combined-cycle and steam system, and this study analyzes GHG emissions of this power plant. The mean GHG emissions $\left(\mathrm{CO}_{2}\right)$ from the Neka Power Plant (steam and combined-cycle) using primary fuels (natural gas and heavy oil) for generating $1 \mathrm{~kW}$ energy are shown in Table 1. As the fluidized bed dryer used in this experiment is driven by electricity from this power plant, the total $\mathrm{CO}_{2}$ emissions due to the drying process is evaluated under the different power house/fuel type scenarios in Table 1. In each case, the total $\mathrm{CO}_{2}$ emissions is the product of the conversion factor and the corresponding total energy consumption $\left(\mathrm{E}_{\mathrm{th}}+\mathrm{E}_{\mathrm{mech}}\right)$, in $\mathrm{kWh}$, with allowances made for power plant, transmission line and distribution losses (a total of 16.45\%).

Table 1. $\mathrm{CO}_{2}$ emissions and pollutants from power plant of Neka

\begin{tabular}{lll}
\hline Power House Type & Fuel type & $\mathbf{C O}_{2}$ Conversion Factor $(\mathbf{g} / \mathbf{k W h})$ \\
\hline Combine-cycle & Natural Gas & 450 \\
& Gas oil & 622 \\
Steam & Natural Gas & 63 \\
& Heavy Oil & 1025 \\
\hline
\end{tabular}

\section{Result and discussion}

\subsection{The effect of drying conditions on specific energy consumption}

The specific energy consumption and the total energy required under the different conditions of fluidize bed drying E. amoenum petals are presented in Fig. 2. An analysis of the results shows that the minimum specific energy consumption of $22.56 \mathrm{MJ} / \mathrm{Kg}$ occurs at $60^{\circ} \mathrm{C}$ air temperature and $0.5 \mathrm{~m} / \mathrm{s}$ air velocity, while the maximum specific energy consumption of 
79.18 $\mathrm{MJ} / \mathrm{Kg}$ occurs at $40^{\circ} \mathrm{C}$ air temperature and $1 \mathrm{~m} / \mathrm{s}$ air velocity. This implies that, the maximum specific energy consumption is approximately 3.5 times the minimum specific energy consumption. The energy required for fluidized bed drying of E. amoenum petals is observed to decrease with temperature, and increase with air velocity. This is partly attributable to the reduction in drying time with increasing air temperature, Also, at any given temperature, the specific energy consumption and the total energy required were higher at higher fluidization velocity, because higher air velocity did not reduce the drying time considerably due to the fact that the moisture transfer inside the material was controlled by the diffusion process. Similar findings have also been reported by other researchers. A higher air velocity reduces the proportion of the input energy utilized by the dryer, thus, increasing the heat losses in the dryer exhausts. This implies increased energy consumption.

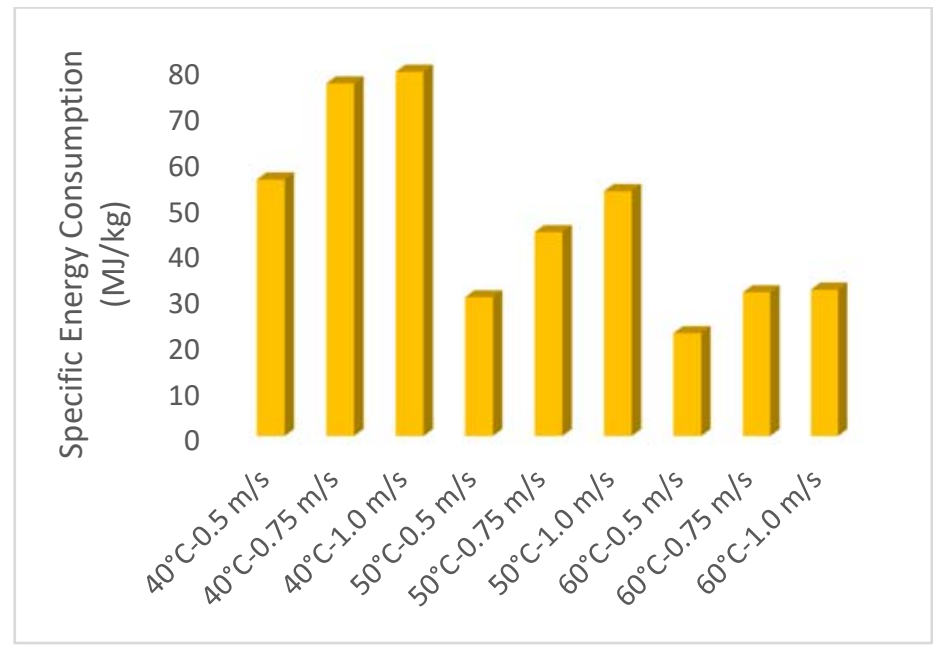

Fig. 2 The effects of different drying conditions on the specific energy consumption

\subsection{The effects of drying conditions on $\mathrm{CO}_{2}$ emissions}

Fig. 3 shows the $\mathrm{CO}_{2}$ emissions by the Neka Power Plant, which is a combined-cycle and steam plant, using different fuels for drying $1 \mathrm{~kg}$ of $E$. amoenum petals. This figure shows the variations in temperature and air velocity in a fluid bed dryer and the corresponding $\mathrm{CO}_{2}$ emissions. Increasing the air flow leads to increased $\mathrm{CO}_{2}$ emissions due to the corresponding increased energy consumption. The emissions however, decrease with temperature as a result of the corresponding drop in the energy consumption. The least $\mathrm{CO}_{2}$ emissions occur at $60^{\circ} \mathrm{C}$ and $0.5 \mathrm{~m} / \mathrm{s}$, while the maximum occurs at $40^{\circ} \mathrm{C}$ and $1 \mathrm{~m} / \mathrm{s}$. As Fig. 2 shows, the maximum $\mathrm{CO}_{2}$ production for all the studied drying conditions occurs for the combined-cycle-gas oil power plant, while the minimum occurs for the steam-natural gas plant. The maximum $\mathrm{CO}_{2}$ 
emissions recorded for the combined-cycle-gas oil power plant at $40^{\circ} \mathrm{C}$ and $1 \mathrm{~m} / \mathrm{s}$ was approximately 80.3 times, its level at the steam-natural gas plant at $60^{\circ} \mathrm{C}$ and $0.5 \mathrm{~m} / \mathrm{s}$.

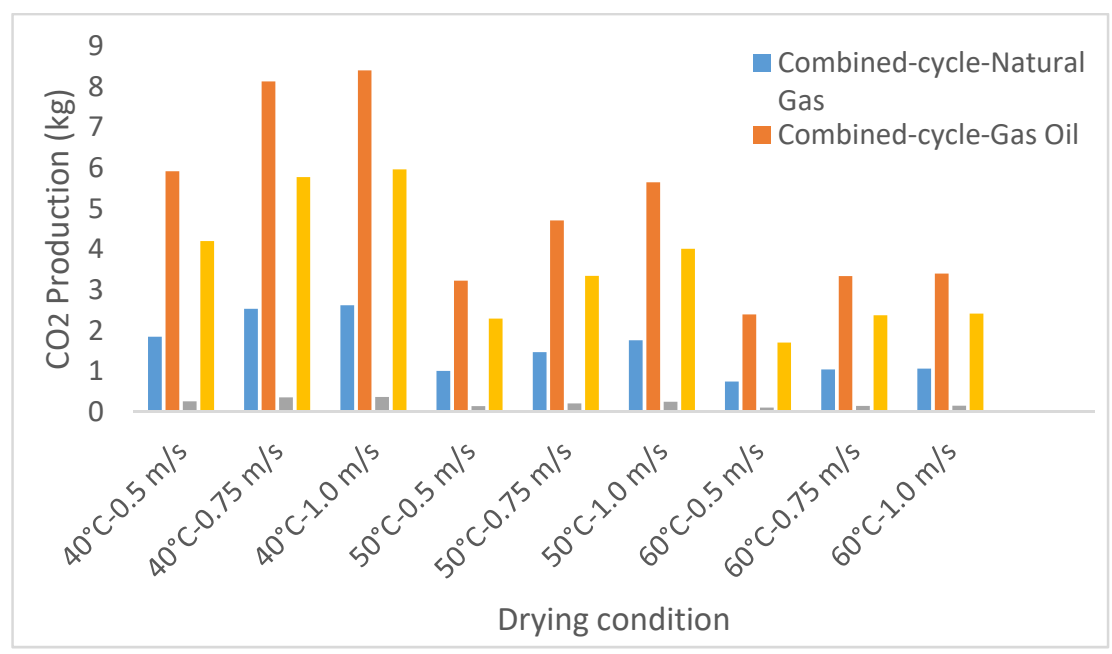

Fig. 3 The effect of in temperature and air velocity variations in a fluid bed dryer on carbon emissions of power plants

\section{Conclusion}

In this study, the effect of drying air velocity and temperature on energy consumption and greenhouse gas $\left(\mathrm{CO}_{2}\right)$ emissions from a fluidized bed dryer was evaluated. From the results, the total energy consumption increased with air velocity for each drying temperature, and decreased with temperature for each air velocity. The GHG $\left(\mathrm{CO}_{2}\right)$ emission levels also varied with drying air temperature and velocity in the same manner. The lowest carbon footprint occurs when the natural gas-fired steam plant is used, while the highest corresponds to the use of oil-fired combined-cycle power plant. High-temperature, low-air velocity drying is thus, advantageous for the fluidized bed drying of Echium amoenum Fisch. and C.A. Mey petals, from a sustainability viewpoint.

\section{References}

[1] Rechinger, K.H. Flora Iranica; Akademische Druck- Und Verlagsanstalt: Graz, 1967.

[2] Hooper, D. Useful Plants and Drugs of Iran and Iraq; Field Museum of Natural History: Chicago, 1937.

[3] Amin, Gh.R. Popular Medicinal Plants of Iran. Press; Iranian Research Institute of Medicinal Plants: Tehran, 1991.

[4] Motevali, A.; Amiri Chayjan, R. Effect of various drying bed on thermodynamic characteristics. Case Studies in Thermal Engineering 2017, 10, 399-406. 
[5] Nadi, F. Bioactive compound retention in Echium amoenum Fisch. \& C. A. Mey. petals: Effect of fluidized bed drying conditions. International Journal of Food Properties 2017, 20(10), 2249-2260.

[6] Hoebink, J.H.B.J.; Rietema, K. Drying granular solids in fluidized bed. Chemical Engineering Science 1980, 35, 2135-2140.

[7] Giner, S.A.; Michelis, A. D.E. Evaluation of the thermal efficiency of wheat drying in fluidized beds: influence of air temperature and heat recovery Journal of Agricultural Engineering Research 1988, 41, 11-23.

[8] Peglow, M.; Cunäus, U.; Tsotsas, E. An analytical solution of population balance equations for continuous fluidized bed drying. Chemical Engineering Science 2011, 66(9), 1916-1922.

[9] Atuonwu, J.C.; van Boxtel, A.J.B.; van Deventer,H.C.; van Straten. G. On the controllability and energy sensitivity of heat-integrated desiccant adsorption dryers. Chemical Engineering Science 2012, 80(1), 134-147.

[10] Mujumdar, A.S. Principles, classification and selection of dryers. In Handbook of Industrial Drying; Mujumdar A.S., Eds.; CRC Press: Florida, 2007.

[11] Kemp, I.I.C. Fundamentals of Energy Analysis of Dryers. In Modern Drying Technology; Tsotsas E.; Mujumdar, A.S. Eds.; Wiley-VCH: Weinheim, 2014.

[12] Piacentini, R.P.; Mujumdar, A.S. Climate Change and Drying of Agricultural Products. Drying Technology 27, 2009 27(5), 629-635.

[13] Singh, S.; Kumar, S. Solar drying for different test conditions: Proposed framework for estimation of specific energy consumption and CO2 emissions mitigation. Energy 2013. $51,27-36$.

[14] Kumar, A.; Kandpal, T.C. Solar drying and CO2 emissions mitigation: potential for selected cash crops in India. Solar Energy 2005, 78, 321-329.

[15] Motevali, A.; Tabatabaee Koloor, R. A comparison between pollutants and greenhouse gas emissions from operation of different dryers based on energy consumption of power plants. Journal of Cleaner Production 2017, 154, 445-461.

[16] Nadi, F., Development of a New Model for Mass Transfer Kinetic of Petals of Echium Amoenum Fisch \& Mey under Fluidized Bed Conditions. Food Tevhnology and Biotechnology, 2016. 54(2): p. 217-227.

[17] Perry, H. Chemical engineer's handbook; McGraw Hill: New York, 1984. 